\title{
ARTIGOS
}

\section{FORMAÇÃO POR COMPETÊNCIA: DISCUTINDO A FORMAÇÃO DE PILOTOS NO BRASIL}

REJANE DE SOUZA FONTES • CLAUDIA MUSA FAY

\section{RESUMO}

0 artigo se propõe, com base em uma revisão bibliográfica, apresentar uma discussão sobre a trajetória da formação do piloto no Brasil e o paradigma de sua formação baseada em competência. Apresenta como objeto de análise a licença de Piloto de Tripulação Múltipla [Multi-crew Pilot Licence] - MPL. A licença de MPL, a primeira criada em mais de quarenta anos de existência da Organização de Aviação Civil Internacional - ICAO -, introduziu um debate sobre a formação do piloto diante dos avanços tecnológicos produzidos pela indústria aeronáutica e o processo de automação das aeronaves. Embora ainda não haja dados suficientes para comprovar a eficácia da licença de MPL, resultados preliminares apontam que sua formação baseada em competência pode ser igual ou superior à formação do piloto tradicional.

FORMAÇÃO PROFISSIONAL • COMPETÊNCIA • SEGURANÇA • LICENÇA DE PILOTO DE TRIPULAÇÃO MÚLTIPLA - MPL

\section{COMPETENCY-BASED TRAINING: DISCUSSING THE TRAINING OF PILOTS IN BRAZIL}

\section{ABSTRACT}

The article proposes to present a discussion regarding the training path of pilots in Brazil and their competency-based training paradigm, according to a literature review. It presents as an object of analysis the multiple crew pilot licence - MPL. The MPL licence is the first one created in over forty years of the existence of International Civil Aviation Organization - ICAO. It has introduced a debate about pilot training facing the technological advances produced by the airline industry and the automation processes of aircraft. Although there is not yet enough data available to prove the efficacy of the MPL licence, preliminary results show that competency-based training can be equal or better than traditional pilot training. 


\section{FORMATION PAR COMPÉTENCE: DISCUSSION SUR LA FORMATION DE PILOTES AU BRÉSIL}

RÉSUMÉ

L'article propose, à partir d'une révision bibliographique, une discussion sur la trajectoire de formation des pilotes au Brésil et le paradigme de leur formation basée sur la compétence. L'objet d'analyse proposé est la licence de Pilote en Équipage Multiple [Multi-crew Pilot Licence] - MPL. La licence MPL, la première dans plus de quarante ans d'existence de l'Organisation de l'Aviation Civile Internationale - ICAO -, a introduit un débat sur la formation des pilotes par rapport aux avancées technologiques de l'industrie aéronautique et le processus d'automation des aéronefs. Bien qu'il n'y ait pas encore de données suffisantes pour prouver l'efficacité de la licence MPL, des résultats préliminaires indiquent que la formation basée sur la compétence peut être égale ou supérieure à la formation du pilote traditionnel.

FORMATION PROFESSIONNELLE • COMPÉTENCE • SÉCURITÉ • LICENCE DE PILOTE EN ÉQUIPAGE MULTIPLE - MPL

El artículo se propone, en base a una revisión bibliográfica, a presentar una discusión sobre la trayectoria de la formación de piloto en Brasil y el paradigma de su formación basada en la competencia. Presenta como objeto de análisis la licencia de Piloto de Tripulación Múltiple [Multi-crew Pilot Licence] - MPL. La licencia de MPL, la primera creada en más de cuarenta años de existencia de la Organización de Aviación Civil Internacional -ICAO-, introdujo un debate sobre la formación del piloto frente a los avances tecnológicos producidos por la industria aeronáutica y el proceso de automación de las aeronaves. Aunque no haya suficientes datos para comprobar la eficacia de la licencia de MPL, resultados preliminares señalan que su formación basada en competencia puede ser igual o superior a la formación de un piloto tradicional. 


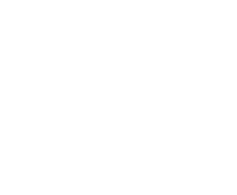

OM O ADVENTO DE AERONAVES CADA VeZ MAIS aUtOMATIZADAS DEVIDO aOS aVANÇOS tecnológicos, o piloto, mais do que o condutor manual, assumiu o papel de gerenciador de sistemas computacionais que monitoram a automação da aeronave. Isso levou a uma mudança de paradigma em sua formação, que deixou de empregar força física no controle da aeronave para desenvolver competências e habilidades de gerenciamento de sistemas de voo, obrigando-o a um nível de conhecimento mais elevado.

Rondon, Capanema e Fontes (2014) afirmam que, com a automação das aeronaves modernas, é possível identificar uma diminuição na utilização das habilidades motoras do piloto de décadas atrás e um aumento das habilidades cognitivas na realização de operações aéreas que o piloto atual deve dominar. Para eles,

Essa característica atual das operações aéreas, a mudança de um "paradigma analógico" para um "paradigma digital", modifica o modus operandi da aviação. Pilotos precisam agora aprender a lidar com as técnicas de gerenciamento dos sistemas automatizados e obter informações precisas do enorme volume de dados obtidos pelos computadores das aeronaves em tempo real. (RONDON; CAPANEMA; FONTES, 2014, p. 54)

É fato que a introdução de sistemas cada vez mais autônomos propiciou o afastamento do piloto do comando manual da aeronave, 
reduzindo, muitas vezes, sua compreensão global do sistema e limitando suas ações a momentos críticos de interferência e controle mecânico do equipamento. E é nesse momento que o paradigma digital requer do piloto habilidades diferentes das que eram exigidas em um ambiente caracterizado pelo paradigma analógico, quando o piloto tinha total controle manual da aeronave.

A melhoria na qualificação do piloto é uma demanda do crescente processo de automação das aeronaves que inaugurou um novo paradigma na relação homem-máquina e no conceito de voar (RONDON; CAPANEMA; FONTES, 2014). Dados estatísticos demonstrados pela Boeing Co. registraram que 62\% dos acidentes aéreos de aeronaves de grande porte são causados por erro humano. Nesses acontecimentos existem muitos fatores contribuintes, dentre os quais se destaca a operação indevida do equipamento por falta de conhecimento necessário das novas tecnologias (BILLINGS; REYNARD, $1984^{1}$ apud RIBEIRO, 2008).

A fim de superar esse impasse, o relatório da Administração Federal de Aviação [Federal Aviation Administration] - FAA ${ }^{2}$ - (UNITED STATES, 2003) já sugeria explorar nos programas de treinamento oportunidades adicionais de segurança de novas tecnologias ou operar dentro das limitações dessas tecnologias, incluindo o desenvolvimento de competências que levassem o piloto a fazer avaliações mais precisas do risco de voo, bem como gerir o risco de voo corretamente em situações que tradicionalmente causam acidentes fatais, como operações anormais.

Nesse sentido, a formação por competências e definir quais seriam essas competências na formação do piloto para o gerenciamento de aeronaves cada vez mais sofisticadas têm sido apontadas como uma necessidade primordial na visão da comunidade aeronáutica (RONDON, 2012).

Diante dessa mudança de paradigma na operação técnica da aeronave, uma mudança de paradigma na formação do piloto também mostrou-se necessária, levando a Organização da Aviação Civil Internacional [International Civil Aviation Organization] - $\mathrm{ICAO}^{3}$ - a mobilizar-se para a criação de uma nova licença que refletisse os anseios do mercado aeronáutico e os avanços dessa nova era tecnológica: a licença de Piloto de Tripulação Múltipla [Multi-crew Pilot Licence] - MPL -, cujos prós e contras passaremos a analisar.

\section{MPL: UM NOVO PARADIGMA DE FORMAÇÃO DE PILOTOS}

A licença de MPL é a primeira a ser introduzida nos regulamentos da ICAO em mais de 40 anos desde sua publicação, em 1948, quando foram criadas as licenças tradicionais de piloto: piloto privado - PP -, piloto comercial - PC - e piloto de linha aérea - PLA. A MPL foi introduzida em 2006, no documento intitulado Anexo 1 da

1 NGS, C. E.; REYNARD, W. D. Human factors in aircraft incidents: results of a 7-year study. Aviation, Space, and Environmental Medicine, n. 55, p. $960-965$, Oct. 1984.

2

A FAA é uma autoridade nacional dos Estados Unidos com poderes para regular todos os aspectos da aviação civil. Estes incluem a construção e operação de aeroportos, a gestão do tráfego aéreo,

a certificação de pessoal e aeronaves, e a proteção dos interesses norte-americanos durante o lançamento ou a reentrada de veículos espaciais na atmosfera. No Brasil, essas ações, com exceção da gestão do tráfego aéreo, que é da competência do Ministério da Aeronáutica - Decea são de responsabilidade da Agência Nacional de Aviação Civil - Anac.

\section{3}

A ICAO é uma agência especializada vinculada à Organização das Nações Unidas - ONU -, criada em 1944, durante a Convenção de Chicago (EUA), com o propósito de regulamentar o espaço aéreo internacional, garantindo a paz e a soberania das nações sobre seu território. Com sede em Montreal (Canadá), a ICAO reúne 191 Estados-membros, entre eles o Brasil, e grupos da indústria para chegar a um consenso sobre as normas internacionais e práticas recomendadas de segurança para a aviação civil. 
ICAO, ${ }^{4}$ após questionamentos de companhias aéreas do mundo todo de que o caminho tradicional de treinamento poderia ser melhorado utilizando modernas tecnologias e metodologias de ensino. Contudo, sua implantação tem sido vista com reservas no meio aeronáutico, especialmente no Brasil, que ainda não formou pilotos dentro dessa nova abordagem de formação profissional.

O objetivo dessa recente licença é apresentar um caminho alternativo para a formação inicial e contínua, baseada em competências, a fim de o piloto obter uma documentação que permita a condução de uma aeronave comercial dentro de uma operação com elevado nível de eficiência, eficácia e segurança e que satisfaça o treinamento necessário de uma linha aérea específica. Tal formação profissional busca qualificar o piloto a voar como copiloto, com apenas 240 horas de voo (o que é considerado pouco, tendo em vista as 1500 horas de voo atualmente necessárias à formação do piloto de linha aérea) a partir de um programa de treinamento de voo $a b$ initio, ${ }^{5}$ cujo treinamento corresponderia à evolução de uma licença de piloto privado, passando pela de piloto comercial até alcançar os conhecimentos e experiência necessários, correspondentes a uma certificação de piloto de linha aérea.

O MPL irá atuar em uma aeronave de tripulação múltipla, ou seja, que requer uma tripulação de pelo menos dois pilotos. Um deles é o piloto em comando (o comandante) e o outro é o copiloto (ou primeiro oficial). Todos os aviões de transporte a jato e a grande maioria das aemeio da publicação de documentos chamados "Anexos" à Convenção Internacional de Aviação Civil (Convenção de Chicago, 1944). Cada anexo trata de um tema específico. Assim, em seus 19 anexos, são abordados alguns dos seguintes assuntos: Licenças de Pessoal (Anexo 1) Regras do Ar (Anexo 2); Cartas Aeronáuticas (Anexo 4); Operação de Aeronaves (Anexo 6); Busca e Salvamento (Anexo 12); Investigação de Acidentes de Aviação (Anexo 13); Segurança: Proteção da Aviação Civil Internacional Contra Atos de Interferência llícita (Anexo 17), etc. A relação completa dos Anexos da ICAO encontra-se disponíve no site: <www.icao.int/>. Acesso em: out. 2016 ronaves de turbina e jatos executivos são aviões de tripulação múltipla.

De acordo com Schroeder e Harms (2007), a formação do piloto MPL tem sido vista com resistência pelos membros da comunidade aeronáutica, inclusive no Brasil. Para muitos, o MPL foi um programa que surgiu como contramedida à escassez de tripulantes na Ásia, especialmente na China e na Índia - países nos quais o quantitativo não conseguiu acompanhar o fluxo de crescimento da indústria aeronáutica -, o que diminuiu o tempo e os custos de investimento na formação. A questão levantada é que, acelerando o processo de formação, haveria mais copilotos disponíveis para as companhias aéreas, mas aumentariam os riscos à segurança. Para os autores que defendiam a proposta (IATA, 2011, 2013, 2015; WIKANDER; DAHLSTRÖM, 2014), a licença de MPL simplesmente reconhecia os avanços significativos na metodologia e tecnologia para a formação, uma vez que, quando o painel da ICAO convocou sua primeira reunião, em 2002, para realizar a atualização das disposições internacionais de treinamento constantes do Anexo 1, a comunidade da aviação ainda sentia as repercussões dos atentados de 11 de setembro de 2001, nos Estados Unidos, a partir de quando se reprimiu a demanda de serviços de transporte aéreo em todo o mundo. Contudo, sabemos que a escassez de pilotos no mundo integra um ciclo sazonal, visto que os ciclos econômicos na indústria da aviação são 
muito curtos, impelidos pelo crescente aumento de passageiros e nichos regionais ainda inexplorados.

Para o grupo de especialistas que participavam do painel da ICAO, realizado em 2002, era óbvio que 40 anos depois da publicação do Anexo 1, a metodologia de formação não mais acompanhava as melhores práticas da indústria, bem como não refletia as possibilidades oferecidas por dispositivos de treinamento avançados, especialmente na área de simulação de voo de alta fidelidade. Além disso, era urgente incorporar ao treinamento de pilotos novos conceitos relacionados ao gerenciamento de ameaças e erros como um princípio que elevaria o nível de segurança das operações de voo.

A fim de buscar subsídios para o debate nacional, realizamos uma pesquisa com 39 pilotos brasileiros, formados entre os anos de 1990 e 2015 no curso de Ciências Aeronáuticas da Pontifícia Universidade Católica do Rio Grande do Sul - PUC-RS -, que atuam em aeroclubes, companhias aéreas nacionais e estrangeiras, como Copa Airlines, Emirates, Aerosat, Qatar Airways, Ethiard, China Eastern. Os dados revelaram que $88 \%$ acreditam que houve mudança na sua formação ao longo dos anos, sendo que para 65\% a atual formação desse profissional atende aos avanços tecnológicos ocorridos na aviação.

Acredita-se que a melhora no nível de formação do piloto se deve, em parte, ao surgimento da formação em nível superior promovida pelas universidades brasileiras, uma vez que ainda não existe no Brasil curso de MPL homologado pela Agência Nacional de Aviação Civil - Anac - para uma análise comparativa.

Outro dado relevante é que 61\% desses pilotos têm conhecimento da licença de MPL; contudo 50\% dos entrevistados afirmaram que são contra a implementação desse tipo de licença, $46 \%$ se disseram a favor e $4 \%$ afirmaram que não possuem opinião formada a respeito.

Quando interrogados se eram a favor ou contra a implantação da licença de MPL no Brasil, alguns pilotos ofereceram depoimentos embasados numa experiência internacional já em andamento, conforme o texto a seguir:

\footnotetext{
Totalmente a favor. Na Qatar Airways trabalho como Fleet training manager do A330/340 e 350. Implantamos MPL primeiramente no A320. O treinamento é muito mais rápido, e o piloto aluno já vem com uma bagagem muito maior em termos de conhecimento da aeronave, já que o tempo em simulador de voo é maior que o convencional. Os resultados estão sendo muito positivos. (Piloto A, 10/11/2015)
}

Houve ainda depoimentos que destacaram as habilidades não técnicas do piloto, num forte indício de formação por competências. 
Sou a favor da implementação do MPL, pois o MPL possibilita desenvolver não só as habilidades técnicas, mas principalmente as habilidades não técnicas. Dessa forma, o piloto formado através do MPL é um piloto que estará pronto para lidar não só com os eventos treinados mas com qualquer tipo de situação. (Piloto B, 16/11/2015)

Outros pilotos, porém, demonstraram intensa oposição à ideia de uma nova licença, valorizando a aviação “pé e mão” em detrimento da certificação acadêmica.

Sou totalmente contra pessoas ESTRANHAS AO MEIO serem credenciadas a avaliar, julgar, opinar sobre o que NÃO CONHECEM a fundo (teoria é bem diferente da prática), nem tampouco sejam titulares de licenças PERTINENTES, a exemplo do amadorístico teste de Inglês da ANAC. [...]. Quero uma aviação onde o aviador VOLTE a voar na mão, ainda que o automatismo seja também muito bem-vindo. (Piloto C, 13/11/2015)

A licença de MPL inicialmente parecia significar algo diferente para cada pessoa que expressasse uma opinião a respeito. Foram muitos os pontos de vista em debate, cujas opiniões variavam desde a crença de que fora projetada como solução rápida e econômica para a falta de pilotos no mundo até as limitações do programa, que ampliava as horas de voo em dispositivos de treinamento em detrimento das horas de voo realizadas em aeronave.

No Brasil, o assunto ainda está sendo debatido, mas já encontra respaldo na legislação aeronáutica por meio do Regulamento Brasileiro de Aviação Civil - RBAC - n. 61:

61.117 (a) O candidato a uma licença de piloto de tripulação múltipla deve cumprir todos os requisitos de conhecimentos teóricos referentes à concessão de licença de piloto de linha aérea na categoria avião constantes da seção 61.137 deste Regulamento.

61.121 (a) O candidato a uma licença de piloto de tripulação múltipla deve:

(1) ter realizado, no mínimo, 240 (duzentas e quarenta) horas de voo real e simulado, em um curso de piloto de tripulação múltipla aprovado pela ANAC;

[...]

$\mathbf{6 1 . 1 2 3}$ (b) A ANAC avaliará continuamente o progresso atingido com o acréscimo do exame de proficiência indicado nesta seção.

(c) A ANAC exercerá vigilância permanente durante a fase inicial de implantação da licença de tripulação múltipla, devendo existir 
uma estreita coordenação e cooperação entre a ANAC, os centros

de instrução e treinamento e as empresas de transporte aéreo que contratarem titulares deste tipo de licença.

61.125 (a) As prerrogativas e condições para o exercício das funções mencionadas no parágrafo 61.111(a) deste Regulamento referem-se ao piloto devidamente qualificado para exercer a função de segundo em comando em um avião certificado para operação com tripulação mínima de 2 (dois) pilotos, e com vínculo empregatício com a empresa que o treinou na função de piloto de tripulação múltipla. (BRASIL, 2012)

Como se vê, a formação exige do aluno piloto a aquisição de domínio dos fundamentos do voo inerentes à concessão de licença de piloto de linha aérea na categoria avião, dentro de 240 horas de voo real e simulado, em um curso de piloto de tripulação múltipla aprovado pela Anac.

Ressalta-se que a formação do piloto dentro da filosofia da licença de MPL não o habilita para o comando de um monomotor ou de uma aeronave tipo, ${ }^{6}$ mas sim para a função de copiloto em um avião de motor a turbina (motor a reação ou turboélice), certificado para operação com tripulação mínima de dois pilotos, bem como não o autoriza a pilotar sozinho uma aeronave, por menor e menos complexa que seja.

Destaca-se, porém, que, entre as prerrogativas do titular da licença de piloto de tripulação múltipla e as condições a serem observadas para exercê-las, encontra-se o vínculo empregatício com a empresa que o treinou na função de piloto de tripulação múltipla. Ou seja, a atividade profissional do piloto ficaria vinculada exclusivamente à empresa de linha aérea que ofereceu treinamento prático na função de copiloto de tripulação múltipla.

Um fato interessante é relatado por Wikander e Dahlström (2014): em agosto de 2008, a Sterling Airlines, companhia aérea dinamarquesa, demitiu 61 funcionários, incluindo os nove primeiros MPL formados no mundo, como resultado de uma crise financeira que combinou elevação dos preços do combustível e recessão econômica. Quando os pilotos MPL foram procurar emprego em outras companhias, lhes foi sugerido que convertessem sua licença para a de um piloto comercial e, em seguida, cumprissem o currículo de formação tradicional para a aquisição da licença de piloto de linha aérea. O que vemos, nesse caso, é o total descarte do programa de formação para a obtenção da licença de MPL em prol da formação do piloto nos moldes tradicionais.

Nesse sentido, alguns questionamentos são pertinentes: como fica a atividade aérea, caso o piloto não seja contratado pela empresa que o treinou? Caso perca seu vínculo empregatício, como se colocará novamente no mercado de trabalho, uma vez que o exercício de sua apresenta uma operação mais complexa que requer um treinamento avançado e focado apenas na sua operação. Geralmente são aeronaves multimotoras e de duplo comando, com exceção do helicóptero, que, apesar de exigir apenas um piloto para sua operação, é considerado aeronave tipo no Brasil. 
atividade profissional está vinculado à empresa aérea que o qualificou como MPL? Poderá o piloto exercer suas prerrogativas da licença como piloto privado? Poderá o piloto exercer suas prerrogativas da licença como piloto comercial? Poderá o piloto exercer suas prerrogativas da licença em voo IFR 7 ? Poderá o titular de uma licença de MPL tornar-se um piloto de linha aérea em comando? O que é necessário a um piloto MPL graduado num A320 para pilotar um B737 ou uma aeronave Embraer?

Para alguns centros de treinamento, o principal problema da formação do MPL residiria nas diferenças entre a estrutura dos cursos em diferentes países, dada a tentação, aparentemente irresistível, de incluir componentes existentes de cursos tradicionais, como a adoção de testes teóricos tradicionais em vez de testes que demonstrem competência.

O curso de piloto tradicional estabelece conhecimentos mínimos previstos nos pré-requisitos para obtenção da licença. Já o objetivo do curso de MPL seria desenvolver as habilidades, conhecimentos e atitudes necessários para executar eficazmente as manobras da aeronave. Se o piloto demonstrar que pode executar todos os aspectos do trabalho dentro do padrão de desempenho esperado, lhe é concedida a licença. Nesse sentido, a formação MPL parece ser uma tarefa mais exigente do que a formação do piloto de linha aérea, pois trabalha com padrões de controle de qualidade mais elevados do que os cursos tradicionais de piloto. Além disso, o desempenho do aluno piloto pode ser avaliado de forma contínua em todos os elementos de cada fase de instrução.

A ideia por trás do conceito é concentrar o treinamento nas habilidades reais necessárias em um cockpit de uma aeronave moderna, em vez de um valor pré-fixado de horas de voo, como ocorre na formação tradicional. Esta se baseia na quantidade fixa de tempos de treinamento. Na abordagem tradicional baseada em resultados, uma vez que os requisitos de tempo tenham sido cumpridos, presume-se que os objetivos de formação tenham sido atingidos. Ou seja, na formação MPL o objetivo seria alinhar os conteúdos do treinamento com as competências reais necessárias à operação aérea.

Em comparação com os métodos tradicionais de treinamento,

IFR [Instrument Flight Rules] significa "regras do voo por instrumentos". É o conjunto de regras utilizadas pelo piloto para conduzir uma aeronave orientando-se pelos instrumentos a bordo. O voo IFR acontece quando o piloto não utiliza as referências visuais externas à aeronave, seja em função da altitude da navegação, da realização do voo durante a noite ou devido a condições meteorológicas que impeçam sua visibilidade. a formação de um MPL faz maior uso de simuladores, adota métodos baseados em formação por competências e aplica-se a fatores humanos e gestão de ameaças e erros em todas as fases de treinamento. Observa-se que os métodos tradicionais de formação caracterizam-se por enfatizar a independência e as habilidades individuais do piloto. Embora adequados para operações de piloto que voa solo, eles podem impedir a transferência dessas habilidades para operações de tripulação múltipla, ampliando as probabilidades de um acidente/incidente aeronáutico, quando na condução de aeronaves mais complexas, em que é exigido um gerenciamento dos sistemas de voo e de recursos de cabine. 
Em 2006, a ICAO emitiu um conjunto de procedimentos para formação e treinamento do piloto que trata dos procedimentos para os serviços de navegação aérea (PANS-TRG), publicado no DOC 9868 (ICAO, 2006), cuja abordagem enfatiza a formação baseada em competências (Competency-based training - CBT) e desloca o foco dos requisitos das horas prescritas de voo para o treinamento e a avaliação com base em competências. Através do PANS-TRG (DOC 9868), a formação do MPL é o sistema de treinamento mais bem documentado da história da ICAO.

\begin{abstract}
Formação baseada em competência: formação e avaliação orientadas para o alcance de um desempenho, com ênfase em padrões de desempenho e sua medição a partir da formação direcionada para os níveis de desempenho especificados. ${ }^{8}$ (ICAO, 2014, p. xi, tradução nossa)
\end{abstract}

O sucesso do programa tem sido creditado ao melhor aproveitamento do processo de instrução direcionada a cada piloto, ao custo mais acessível e ao tempo reduzido da formação do piloto dentro de uma perspectiva de otimização de tempo e recursos. Além disso, o aluno deverá ter adquirido experiência necessária para alcançar o nível avançado de competência requerido - o que é um conceito novo dentro da aviação.

A licença de MPL trouxe, assim, a necessidade de se rever a formação do piloto e serviu para implementar a metodologia de formação baseada em competências, que deverá, futuramente, ser seguida nos demais cursos de formação para obtenção das outras licenças na área de aviação.

A formação baseada em competência nasce apoiada na ideia de que o domínio do conhecimento deve ser demonstrado, de forma individual, através de sua aplicabilidade dentro do trinômio: conhecimentos/ habilidades/atitudes - CHA.

\section{A FORMAÇÃO POR COMPETÊNCIAS NA AVIAÇÃO}

O conceito de competência surgiu na Europa na década de 1980, dentro de um contexto de crise do modelo de produção taylorista/fordista, globalização econômica, elevação da competição entre os mercados e demandas por flexibilização dos processos de produção e de trabalho. Como modelo de formação voltada para o ensino técnico-profissionalizante, a pedagogia das competências foi implementada inicialmente na França, também nos anos 1980, e centrava-se nos conceitos de saberes e ações avaliados através de desempenhos individuais altamente especializados (DELUIZ, 2004).
8

No original: "Competency-based training. Training and assessment that are characterized by a performance orientation, emphasis on standards of performance and their measurement and the development of training to the specified performance standards". 
No Brasil, a concepção de competência começou a ser discutida nos anos 1990 numa tentativa de romper a dualidade imposta ao sistema de ensino médio no país: formação profissionalizante, destinada ao mercado de trabalho, versus formação propedêutica, que dava acesso à universidade.

Durante muito tempo, a escolarização no Brasil, como herança da educação dos jesuítas, pautou-se pela ideia da educação bancária, em que o professor transmitia o conteúdo para o aluno de forma dogmática e escalonada. Tal ensino, de caráter essencialmente conteudista, mostrou-se ineficaz ao longo do tempo, pois os alunos não sabiam transferir seus conhecimentos para situações da vida real.

Pensando nessas questões, a formação baseada em competência começou a ganhar destaque no âmbito educacional e tornou-se a diretriz para a elaboração de currículos pautados numa formação mais flexível e continuada, voltada para os desafios tecnológicos impostos pela sociedade contemporânea, em especial, na área de aviação civil.

Esses desafios são fruto da interação do homem com a máquina, que demanda mais do que uma simples reforma pragmática no currículo de formação do piloto; uma mudança paradigmática, orientada a novos arranjos de conhecimentos, atitudes e habilidades, dentro de uma atividade complexa que marca a valorização do conhecimento, do processamento de informações e realização simultânea de diferentes atividades, processamento

\section{[...] no qual o trabalhador multiqualificado, polivalente, deve exer- cer, na automação, funções muito mais abstratas e intelectuais, implicando cada vez menos trabalho manual e cada vez mais a manipulação simbólica. (DELUIZ, 2004, p. 74)}

A formação baseada em competência volta-se para a mobilização, integração e transferência de conhecimentos, atitudes e habilidades necessários ao desempenho de uma determinada atividade ou tarefa com eficiência. A correta mobilização de conhecimentos e habilidades para a execução de uma determinada tarefa proporciona subsídios para a adequada tomada de decisões em situações inesperadas que possam ocorrer no exercício da atividade aérea.

O trinômio CHA, que embasa o conceito de competência, deve ser aqui mais bem compreendido. Entendem-se por conhecimento os conceitos, ideias e teorias sobre determinado assunto que subsidiam a capacidade de pensar, estabelecer conexões entre ideias e diagnosticar soluções para os problemas. É uma atividade puramente intelectual, ainda que o conhecimento advenha da experiência do sujeito no mundo (o saber). Já a habilidade se refere à atividade laboral prática que emprega o conhecimento na execução técnica de uma tarefa. Ou seja, é uma prática que mobiliza conhecimentos para sua execução (o saber fazer). 
Por fim, entende-se por atitude o relacionamento interpessoal que envolve a capacidade de se comunicar, cumprir regras, coordenar, liderar e resolver conflitos (o saber ser).

\begin{abstract}
Em síntese, a realização competente tem nela agregados saberes cognitivos, psicomotores e socioafetivos. A competência caracteriza-se, essencialmente, pela condição de alocar esses saberes como recursos ou insumos, através de análises, sínteses, inferências, generalizações, analogias, associações, transferências, ou seja, de esquemas mentais adaptados e flexíveis, em ações próprias de um contexto profissional específico, gerando desempenhos eficientes e eficazes. (BRASIL, 2000, p. 10)
\end{abstract}

Assim, a competência é a capacidade que o sujeito possui de mobilizar conhecimentos e expressá-los através da execução adequada de uma atividade e da exibição de um comportamento esperado necessários na resolução de um problema. Na aviação, a capacidade de tomar decisões e a experiência estão estreitamente relacionadas na operacionalização de uma competência.

A noção de competência aparece assim associada a expressões verbais como: saber agir, mobilizar recursos, integrar saberes múltiplos e complexos, saber aprender, saber engajar-se, assumir responsabilidades, ter visão estratégica, agregando valor econômico para a organização e valor social para o indivíduo.

Para Fleury e Fleury (2001), a competência individual encontra seus limites no nível dos saberes alcançados pela sociedade ou pela profissão do indivíduo numa determinada época. As competências são sempre contextualizadas. Os conhecimentos e o know how não adquirem status de competência, a não ser que sejam comunicados e utilizados - e vinculados à prática.

O modelo de competência caracteriza-se pela flexibilidade, transferibilidade, polivalência e empregabilidade. No mundo do trabalho, a gestão por competências implica dispor de trabalhadores flexíveis para lidar com as mudanças no processo produtivo a fim de solucionar problemas/conflitos e enfrentar imprevistos (crises/incidentes/eventos), requerendo-se, para tanto, a polivalência e a constante atualização de suas competências. Nada mais emblemático para a formação do piloto do que a necessidade de mobilização de suas competências para resolver as novas situações de trabalho que surgem diante dos eventos imprevistos.

Segundo Deluiz (2001), os saberes não formais, como as qualificações tácitas ou sociais e a subjetividade do trabalhador, assumem grande relevância, enfocando, assim, as características individuais dos trabalhadores. 
É nesse sentido que Ramos (2002) chama atenção para o emprego da noção de competência em detrimento do conceito de qualificação. Quando associada unicamente à dimensão experimental, a competência pode fragilizar os níveis de formação desejados ao bom desempenho profissional. Primeiro, porque, ao valorizar os saberes tácitos e sociais, os saberes acadêmicos tradicionais, atestados por diplomas, ganham importância secundária numa escala de valores sociais. Em segundo lugar, com a crise de empregabilidade e a valorização das potencialidades individuais que vivemos atualmente, sobressai a habilidade experimental do trabalhador. Segundo ela, "apropriações apressadas e limitadas desta noção podem reduzir a educação profissional a práticas voltadas para formações restritas, num triste recuo a princípios educacionais considerados superados" (RAMOS, 2002, p. 403).

No Brasil, como vimos, o aumento da tecnologia embarcada nas aeronaves automatizadas tem levado um número crescente de pilotos à formação universitária, o que evidencia uma valorização da qualificação, se comparada a um treinamento mais aligeirado com base no modelo de formação proposto pelo curso de MPL. Talvez por isso, no país ainda não haja cursos de MPL homologados.

Ao mesmo tempo em que a formação baseada em competência exige que o trabalhador se reinvente constantemente diante das exigências do mundo do trabalho, traz ela também a possibilidade de intelectualização do trabalhador que desenvolve um trabalho menos prescritivo, envolvendo domínios cognitivos mais complexos, que vão além da dimensão técnica. Há uma valorização dos saberes em ação, que lhe permite lidar com diferentes processos e equipamentos, tornando-o multiqualificado para desenvolver competências coletivas a partir do trabalho em equipe, maior comunicação e autonomia para o planejamento, execução e controle dos processos produtivos.

Perrenoud (1999) apresenta alguns questionamentos em relação à matéria competências. Para ele, a argumentação de que as competências somente podem ser expressas através de condutas práticas e observáveis é uma falácia. Não há garantias de que haverá mobilização dos conhecimentos diante de situações complexas da vida profissional. Seguindo a mesma lógica de argumentação, Ramos (2002) defende, com base nos estudos cognitivos de Piaget, que há uma mobilização de saberes e esquemas mentais, nem sempre possíveis de demonstrar na realização de uma atividade, e que ainda assim compõem a competência de um indivíduo. Para ela, as competências profissionais não podem ser reduzidas aos desempenhos observáveis, e a natureza do conhecimento não pode se restringir às competências que ele desencadeia.

A esse respeito, a autora apresenta uma distinção importante entre os conceitos de competência e desempenho (RAMOS, 2001a). Enquanto as competências constituem saberes interiorizados que permitem ao 
sujeito enfrentar situações com iniciativa e responsabilidade, “o desempenho seria a expressão concreta dos recursos que o indivíduo articula e mobiliza no enfrentamento dessas situações” (RAMOS, 2001a, p. 22).

A segunda questão apontada por Perrenoud (1999) diz respeito aos instrumentos de avaliação da competência voltados para desempenhos observáveis, pois esses não devem ser os únicos indicadores confiáveis da competência. Ao se manifestar de diversas formas e ao sinalizar sua existência, mesmo sem condições de se manifestar, a competência deve ser avaliada por instrumentos que dispensem sua observação direta; ou seja, é necessário garantir formas de avaliar que sejam um convite ao raciocínio subjacente. "Se a abordagem de competências não transformar os procedimentos de avaliação - o que é avaliado e como é avaliado - são poucas as suas chances de seguir adiante" (PERRENOUD, 1999, p. 28). Para Ramos (2001a), num processo de avaliação, é o desempenho que pode ser observado diretamente e não as competências, devendo ele ser tomado como objeto de avaliação capaz de inferir sobre um conjunto de competências subjacentes.

Por fim, o autor afirma que a competência é uma construção individual e se realiza de forma diferenciada em cada sujeito, por meio de aprendizagens individuais sobre as potencialidades que cada sujeito apresenta. A essa afirmação contrapõe-se o pensamento de Ramos (2001a, 2001b, 2002), que apresenta contribuições relevantes ao postular que a competência - sob uma lógica de construção individual - refuta-a como projeto de sociedade e transfere ao sujeito toda a carga de responsabilidade por sua formação e adaptação às mudanças sociais e no campo do trabalho. Para a autora, "a construção de saberes efetivamente significativos implica pensarmos a competência numa dimensão humana e social, isto é, para além de uma característica própria do sujeito individual e abstrato" (RAMOS, 2001a, p. 27).

Na mesma linha de argumentação, Deluiz (2001) sinaliza o conceito de competência a partir de uma matriz crítico-emancipatória, em comparação às matrizes behavioristas, funcionalistas ou construtivistas desenvolvidas até então, e com forte ênfase nos resultados esperados pelo mercado de trabalho. Segundo ela, 
Sob essa perspectiva, o currículo deve valorizar os saberes historicamente construídos e promover sua mobilização diante dos desafios práticos impostos pela sociedade contemporânea para ampliar o horizonte de formação e intervenção social desse novo profissional. Do ponto de vista pedagógico, a licença de MPL obriga que cada fase de instrução para a concessão da licença de piloto de tripulação múltipla deva abranger o ensino dos conhecimentos básicos e parte da instrução prática, integrando-se. Essa metodologia de ensino, que deveria ser transposta para a obtenção das demais licenças, indica um amadurecimento da ideia de formação do piloto, que até então se encontrava vinculada a treinamento/adestramento em seu sentido militar.

Para Deluiz (2001), as matrizes curriculares, quando orientadas para a formação baseada em competências, devem seguir algumas orientações básicas: investigação dos processos de trabalho para a identificação de perfis de conclusão; definição dos módulos de competências profissionais; desenho modularizado da estrutura curricular; definição dos itinerários profissionais com pré-requisitos de acesso aos módulos e aos cursos; definição das estratégias de aprendizagem com individualização dos percursos de formação, construção significativa do conhecimento e seleção de situações-problema; e definição do processo de avaliação da aprendizagem.

Ramos (2002) complementa a ideia, apresentando a trilha para a construção do currículo baseado em competência. Primeiramente, a matriz referencial deve partir da análise do processo de trabalho, cujos conteúdos devem ser transpostos para uma organização modular, a ser desenvolvida dentro de uma abordagem metodológica baseada em projetos ou resolução de problemas.

\footnotetext{
Por isso as diretrizes recomendam que os currículos sejam modulares, permitindo aos trabalhadores a construção de seus próprios itinerários de formação, assim como preveem mecanismos de avaliação, que possam certificar competências adquiridas pela experiência profissional. (RAMOS, 2002, p. 406)
}

O treinamento baseado em competências na formação do piloto apoia-se na ideia de que não é possível treinar para situações de emergência e acontecimentos inesperados. Contudo, é possível preparar o piloto para essas situações através da instrução baseada em cenários (resolução de problemas), em que as competências-chave devem ser trabalhadas na formação do piloto do século XXI. A aprendizagem baseia-se, assim, na mobilização de esquemas mentais diante dos desafios reais 
ou simulados impostos pelo meio, o que resultaria em aprendizagens profissionais significativas.

\begin{abstract}
A instrução baseada em cenários possui as seguintes vantagens que proporciona: a) avaliação com critérios de referência mais fáceis e confiáveis; b) controle mais eficaz das condutas demonstradas mediante a seleção de ocorrências e condições diante das quais o aluno deve atuar e c) um processo de design estruturado para integrar a instrução e os exames tanto das competências CRM (Cockpit Resource Management/Gestão de Recursos de Tripulação) e TEM (Threat and Error Management/Gestão de Ameaças e Erros) como das competências técnicas nas fases de voo. $^{9}$ (ICAO, 2006, p. 3-7, tradução nossa)
\end{abstract}

Os Referenciais Curriculares Nacionais da Educação Profissional de Nível Técnico deslocam o foco do trabalho educacional do ato de ensinar para o processo de aprender e do que é preciso aprender para o mundo contemporâneo e do futuro, com explícita valorização do emprego de ferramentas tecnológicas avançadas (BRASIL, 2000). Assim, o aluno pode sair de uma formação inicial $a b$ initio (zero tempo de voo) e alcançar uma licença equivalente à de um copiloto de linha aérea e todo o preparo técnico e responsabilidade que essa função envolve.

É fato que nenhum currículo é capaz de captar as múltiplas dimensões da realidade e as constantes transformações e exigências do mundo do trabalho, mas pode contribuir para a ampliação das capacidades intelectuais do trabalhador, subsidiando-o para o desenvolvimento das competências profissionais desejadas.

A capacidade de tomar decisões e a experiência estão estreitamente relacionadas na operacionalização de uma competência. Tomar uma decisão, muitas vezes, implica certo grau de improvisação, mas uma improvisação orientada pela experiência e pelo conhecimento.

Os principais elementos de competência a serem contemplados na formação do piloto de tripulação múltipla podem ser assim definidos: comunicação; consciência situacional; liderança e trabalho em equipe; gerenciamento da carga de trabalho; resolução de problemas e tomada de decisão; transferência de conhecimento; aplicação correta de procedimentos; gerenciamento de voo automatizado e controle manual da aeronave. Essas competências e seus respectivos critérios de desempenho constituem o conjunto completo de comportamento observável para uma operação segura, eficiente e eficaz de voo de tripulação múltipla (IATA, 2011). Para melhor visualização dessas competências, sua descrição e critérios de performance que embasam a avaliação do aluno, selecionamos quatro desses elementos para discussão.
Scenario-based training has the advantages that it provides: a) easier and more reliable criterion-referenced evaluations; b) more effective control over the behaviours that need to be demonstrated through the selection of occurrences and conditions against which the student has to perform; and c) a structured design process for integrating the training and testing of both CRM and TEM competencies and the technical phase-of-flight competencies". 
A demonstração de aplicação correta de procedimentos, por exemplo, deve ser observada com base na aplicação dos procedimentos de acordo com as instruções contidas nas publicações aeronáuticas. Nessa competência, o critério de performance do aluno é avaliado por meio da observação do uso adequado dos sistemas, controle, instrumentos e manuais de operação, de forma a potencializar o melhor desempenho para a operação da aeronave, incluindo combustível, ambiente, satisfação dos passageiros, conforto e pontualidade, a fim de alcançar e manter a segurança de voo.

A comunicação é um elemento-chave para a formação do piloto, em que ele deve demonstrar o uso adequado da linguagem para feedbacks e resolução de mal-entendidos. Durante a avaliação, observa-se se o aluno sabe o quê, quando, como e com quem precisa se comunicar, além de transmitir informações de forma clara, apurada, tempestiva e adequada. Deve demonstrar ainda que é capaz de assegurar que os outros tenham tido correto entendimento da informação transmitida, assim como demonstrar compreender quando recebe uma informação. Deve fazer perguntas relevantes e efetivas e oferecer sugestões, além de usar apropriadamente a linguagem corporal, o contato visual e interpretar corretamente a comunicação não verbal dos outros tripulantes.

A consciência situacional é outra competência relevante para a formação do piloto. Nela, o aluno deve demonstrar que possui consciência do estado da aeronave no ambiente, projetar e antecipar mudanças. Essa competência traduz-se na afirmativa "voar à frente da aeronave", em que o piloto deve antecipar mentalmente todas as ações que irão acontecer. Nesse sentido, o critério de performance é observado a partir da consciência que o aluno demonstra em relação aos seguintes itens: o que a aeronave e seu sistema estão fazendo; monitoramento da faixa de tempo e combustível; condição das pessoas envolvidas na operação, incluindo os passageiros; reconhecimento do que é provável de acontecer, planejamento e capacidade de permanecer à frente da situação; capacidade de desenvolver possíveis cenários e planos de contingência e identificar ameaças para a segurança da aeronave e das pessoas, tomando as ações apropriadas.

A liderança e o trabalho em equipe são fatores fundamentais para o gerenciamento de um bom voo. Essa competência define-se pelo uso apropriado da autoridade do piloto a fim de garantir o foco na tarefa realizada e dar suporte na realização das atividades dos demais membros da tripulação. A performance do aluno deve ser avaliada a partir da maneira como ele conduz a tripulação; considera a opinião dos outros; tem iniciativa; é responsável com o que lhe é requisitado; antecipa a necessidade dos outros membros da tripulação; está aberto a outras ideias, pensamentos, preocupações e intenções; oferece e recebe tanto crítica como elogios e admite erros; demonstra empatia, respeito e tolerância pelas outras 
pessoas e envolve os outros no planejamento e distribuição de atividades de forma justa e apropriada de acordo com suas habilidades.

A formação e a avaliação por competência baseiam-se essencialmente na padronização dos níveis de conhecimentos e habilidades esperados pela comunidade aeronáutica. Em síntese, o treinamento deve enfatizar a necessidade do piloto de reconhecer uma divergência tão logo seja possível e imediatamente tomar as medidas corretivas e decisões necessárias para retornar a aeronave para a rota planejada.

Os centros de treinamento defendem os seguintes benefícios para o aluno piloto aspirante a uma licença de MPL: um treinamento de elevada qualidade num tempo mais reduzido e o caminho mais rápido para a cabine de um avião comercial. O programa de MPL ajuda as companhias aéreas a reduzir o tempo total e os custos relacionados com a formação $a b$ initio.

O programa de treinamento MPL é dividido em quatro fases conforme definido pela ICAO: Principais habilidades de voo, Básico, Intermediário e Avançado. O programa de MPL incorpora intenso uso de simuladores de voo para desenvolver as habilidades exigidas de um piloto de avião, em especial operações de tripulação múltipla e gestão de ameaças e erros.

A Tabela 1, a seguir, apresenta uma breve descrição das fases do programa de formação.

TABELA 1

NÍVEIS DA FORMAÇÃO BASEADA EM COMPETÊNCIAS PARA A OBTENÇÃO DA LICENÇA DE MPL

\section{PRINCIPAIS HABILIDADES DO VOO}

A primeira parte do programa inclui de 60 a 120 horas de tempo de voo real. 0 aluno piloto participa do treinamento de solo (ground schoo/) utilizando tecnologia moderna e recebe treinamento em uma aeronave monomotora ou multimotora, aprende a gerenciar recursos de tripulação, realizar navegações, reconhecer instrumentos básicos de voo e realiza o primeiro voo solo.

\section{NÍVEL BÁSICO DE COMPETÊNCIA}

O aluno piloto é introduzido em operações de tripulação múltipla e de voo por instrumentos. Além do voo noturno, o aluno será treinado na recuperação do controle da aeronave e no uso das Regras de Voo por Instrumentos (IFR) nos voos de travessia.

NÍVEL INTERMEDIÁRIO DE COMPETÊNCIA

O aluno piloto irá progredir para um simulador de alto desempenho de uma aeronave multimotora, além de instrução de CRM, Line-Oriented Flight Training (LOFT) ${ }^{10}$ e manuseio de situações anormais e de emergência, perigo e gestão de risco.

\section{NÍVEL AVANÇADO DE COMPETÊNCIA}

No nível final do curso, o aluno piloto avança seus treinamentos para um simulador de seis eixos (nível D) e, finalmente, realiza 12 pousos e decolagens como piloto em comando numa aeronave. Após atingir os altos padrões e níveis de competência esperados, o aluno torna-se um MPL qualificado como copiloto de uma aeronave tipo. O piloto é, então, introduzido na linha aérea sob a supervisão de um comandante.

Fonte: DOC 9868 (ICAO, 2006).

No treinamento, prevenção da queda e recuperação do controle da aeronave são elementos novos na formação MPL. Servem para

10

O Line Oriented Flight

Training - LOFT - é

um procedimento de treinamento realizado em um simulador de voo, como parte da formação inicial ou recorrente da tripulação. Inclui uma ênfase especial em situações anormais que envolvem comunicação, gestão e liderança. As situações anormais e de emergência que serão encontradas durante o treinamento não são informadas previamente. 
aumentar a capacidade do piloto para reconhecer, prevenir e evitar situações de perda de controle bem como melhorar sua capacidade de recuperar o controle da aeronave. Além disso, deve incutir mais confiança nas principais habilidades de voo. Isso pode ser feito a qualquer momento durante o curso, de preferência no final da Fase 1 ou na Fase 2. O treinamento ideal para recuperação do controle da aeronave deve consistir numa composição curricular que mescle teoria de voo, lições práticas em aeronaves e simuladores, aspectos sensoriais humanos e características de voo das modernas aeronaves de transporte a jato.

Por outro lado, não se podem desconsiderar completamente as aprendizagens necessárias para o controle manual da aeronave, mesmo que esta possua o controle automatizado - uma vez que, em situação anormal ou de emergência, é necessário que a tripulação esteja preparada e saiba como conduzir a aeronave utilizando suas habilidades manuais. Nesse sentido, os treinamentos práticos em aeronaves tecnologicamente avançadas não podem prescindir dos fundamentos basilares da aviação "pé e mão", conforme demonstrado entre as competências de formação do MPL que prevê, entre outras, o controle manual da aeronave.

Em 2008, o voo 731 da United Airlines perdeu metade de seus painéis, rádios, transponders e TCAS. Felizmente, os pilotos foram capazes de manter o controle do voo manual a fim de pousar de volta em seu aeródromo de partida. A necessidade de manter a arte de pilotar destaca-se, assim, mesmo durante esses tempos de automação." (PEREZ GONZALEZ, 2011, s./p, tradução nossa)

Por fim, vale comentar os resultados do Simpósio sobre MPL realizado pela ICAO em Montreal, em dezembro de 2013, quando se observou que tanto o regulador como as companhias aéreas acreditavam que a licença de MPL preparava tão bem ou até melhor para a carreira de piloto de linha aérea - se comparada aos programas tradicionais de formação de piloto. Porém o número limitado de instrutores qualificados e a ausência de um sistema mais robusto de formação teórica baseada em competências mostraram-se ponto desfavorável para o aumento do número de cursos de formação, que à época contavam com 785 pilotos

No original: "In 2008, United Airlines Flight 731 lost half of its display panels radios, transponders and TCAS. Fortunately, the pilots were able to maintain manual flight control to land back at their departure aerodrome. The necessity to maintain airmanship is thus highlighted even during this age of automation". MPL graduados e 2.471 alunos em formação em todo o mundo.

Com efeito, a transição da formação tradicional para a formação baseada em competência dos cursos de piloto MPL ainda é um desafio e encontra barreira nas legislações locais. Um aspecto problemático é que os reguladores estão mudando e adaptando as intenções da formação baseada em competência de acordo com a realidade de cada Estado, o que dificulta a harmonização da formação em nível global. 


\section{CONSIDERAÇÕES FINAIS}

Com o avanço tecnológico e a automação das aeronaves, a formação do piloto hoje exige um nível de conhecimento cada vez mais elevado, com ênfase em aspectos cognitivos em detrimento da dimensão psicomotora. Isso tem levado um número crescente de pilotos a uma formação em nível superior. Tal conclusão, aliada aos principais acidentes da aviação comercial que ainda apontam falhas sistêmicas na instrução ministrada às tripulações, contribuiu para que a ICAO repensasse o processo de formação de piloto e propusesse uma nova licença: a MPL.

A formação do piloto MPL propõe uma instrução com base em competências e apresenta uma abordagem de formação e treinamento proativa, focada em atender às necessidades de formação de cada indivíduo a fim de reduzir os erros e falhas que têm levado a acidentes. No entanto, apresenta limitações que deverão ser discutidas no futuro, como a ênfase na dimensão experimental do conhecimento em detrimento da qualificação formal, ou a preocupação com o produto (resultados) em oposição aos processos de construção de competências. Ainda não há informação de que um piloto MPL tenha sido promovido a comandante, mas, com o tempo, é provável que essa discussão venha a surgir, já que contém perspectivas sobre a segurança e a economia em relação ao crescimento futuro da indústria aeronáutica.

As atuais ferramentas de treinamento, como simuladores de voo e treinamento baseado em programas de computador, têm o potencial de oferecer uma formação mais rápida e qualificada, cujo treinamento deve ser continuamente reavaliado.

A necessidade de treinamento mais eficaz levou vários Estados a desenvolver requisitos de formação e avaliação baseados em competência. Isso deverá contribuir, no futuro, para redesenhar os cursos de formação de piloto atualmente baseados em metodologias tradicionais.

Contudo, um debate se instalou no meio aeronáutico entre defensores e críticos dessa abordagem de formação. Para alguns, a licença de MPL encontra as seguintes limitações à sua implantação: falta de interesse da indústria, engessamento regulamentar das autoridades aeronáuticas, descrédito na formação aligeirada em tempo reduzido, custos mais baixos, metodologia diferenciada e ideia de degradação da habilitação.

Já para os defensores dessa proposta, é necessário reconhecer que a duração do curso e o número de horas de formação não são critérios significativos para avaliar a qualidade ou o sucesso de um programa de formação baseado em competências. Para eles, o treinamento intensivo focado nas habilidades do aluno e o aumento de horas de uso de simuladores de alta fidelidade, juntamente com uma avaliação continuada da aprendizagem, são os pontos fortes do programa de treinamento. 
Não há dúvidas de que a formação baseada em competências cria um desafio à normalização. Os reguladores em geral parecem ainda não dominar o assunto e lhes falta conhecimento necessário para regular a formação desenvolvida sob uma nova metodologia. Para que o programa seja bem-sucedido, é necessário seu acompanhamento criterioso com as ferramentas necessárias capazes de demonstrar a evolução dos alunos individualmente e o desempenho global da organização, bem como os conhecimentos e habilidades dos instrutores, que também precisam ser desenvolvidos. Tão importante quanto saber o que ensinar é saber como ensinar.

Constata-se certa indefinição quanto ao detalhamento das competências desejadas que os futuros pilotos precisariam dominar e como estas devem ser desenvolvidas dentro de um programa de treinamento voltado para a formação do MPL.

Além da atualização metodológica, também é fundamental rever os requisitos de conhecimentos teóricos que orientam a matriz de formação do piloto e que não passaram por qualquer modernização mais profunda desde sua implementação. Assim, a formação teórica precisa evoluir em relação ao seu conteúdo, inaugurando a instrução e os exames baseados em cenários que explorem as competências-chave essenciais à formação do piloto.

Ainda não há dados suficientes para comprovar a eficácia da licença de MPL, uma vez que menos de um terço dos Estados contratantes da ICAO adotaram a regulamentação MPL e, portanto, ainda há um longo caminho a percorrer. Observa-se, porém, que a formação MPL tem avançado bastante nos últimos anos no setor de treinamento da aviação, especialmente na Ásia e no Oriente Médio. Entre os operadores que recentemente relataram suas intenções de iniciar a formação MPL estão a companhia aérea Japan Airlines - JAL -, a All Nippon Airlines - ANA e a Etihad Airways. A Autoridade de Aviação Civil Geral - GCAA -, nos Emirados Árabes Unidos, também relatou no simpósio MPL uma projeção nacional de mais de 400 pilotos MPL sendo produzidos por ano a partir de 2016 (WIKANDER; DAHLSTRÖM, 2014).

A licença de MPL é, assim, apenas uma das muitas iniciativas possíveis para melhorar a formação e o treinamento de pilotos no Brasil e no mundo; e demanda a cooperação de todos os envolvidos no processo: organizações de instrução, companhias aéreas e reguladores, que definirão o perfil dos pilotos da próxima geração de profissionais da aviação.

\section{REFERÊNCIAS}

AVIATIONKNOWLEDGE. Multi-Crew Pilot License (2). Disponível em: <http://aviationknowledge. wikidot.com/aviation:multi-crew-pilot-license-2>. Acesso em: 6 fev. 2015. 
BRASIL. Ministério da Educação. Referenciais Curriculares Nacionais da Educação Profissional de Nível Técnico. Brasília: MEC, 2000.

BRASIL. Ministério da Educação. Secretaria de Educação Profissional e Tecnológica. Catálogo nacional de cursos superiores de tecnologia. Brasília: MEC, 2010. Disponível em: < http://portal.mec. gov.br/index.php?Itemid=719>. Acesso em: 3 set. 2015.

BRASIL. Agência Nacional de Aviação Civil. Resolução ANAC n. 237, de 05 de junho de 2012. Regulamento Brasileiro de Aviação Civil n. 61 (RBAC 61). Emenda n. 05. Diário Oficial da União n. 120, de 22 de junho de 2012, Seção 1, p. 3.

DELUIZ, N. O modelo das competências profissionais no mundo do trabalho e na educação: implicações para o currículo. Boletim Técnico do SENAC, Rio de Janeiro, v. 27, n. 3, p. 13-25, set./dez. 2001.

DELUIZ, N. A globalização econômica e os desafios à formação profissional. Boletim Técnico do SENAC, Rio de Janeiro, v. 30, n. 3, p. 73-79, 2004.

FLEURY, M. T. L.; FLEURY, A. Construindo o conceito de competência. Revista de Administração Contemporânea, Curitiba, v. 5, p. 183-196, 2001. Edição Especial. Disponível em: <http://www. scielo.br/pdf/rac/v5nspe/v5nspea10.pdf>. Acesso em: 8 jan. 2015.

INTERNATIONAL AIR TRANSPORT ASSOCIATION - IATA. Guidance material and best practices for MPL implementation. $1^{\text {st }}$ ed. Montreal-Geneva, October, 2011. Disponível em: <http://www. iata.org/whatwedo/ops-infra/itqi/Documents/guidance-material-and-best-practices-for-mplimplementation.pdf>. Acesso em: 25 fev. 2015.

INTERNATIONAL AIR TRANSPORT ASSOCIATION - IATA. Evidence-Based Training Implementation Guide. 2013. Disponível em: <http://www.iata.org/whatwedo/ops-infra/itqi/Documents/ebtimplementation-guide.pdf>. Acesso em: 20 fev. 2015.

INTERNATIONAL AIR TRANSPORT ASSOCIATION - IATA. Guidance Material and best practices for MPL implementation. $2^{\text {nd }}$ ed. Montreal-Geneva, July, 2015. Disponível em: <https://www. iata.org/whatwedo/ops-infra/itqi/Documents/guidance-material-and-best-practices-for-mplimplementation.pdf>. Acesso em: 5 nov. 2015.

INTERNATIONAL CIVIL AVIATION ORGANIZATION - ICAO. Convenção de Aviação Civil Internacional. Doc 9868 - Procedures of Air Navigation Services - Training PANS-TRG. First Edition, 2006.

INTERNATIONAL CIVIL AVIATION ORGANIZATION - ICAO. MULTI-CREW PILOT LICENSE SYMPOSIUM. Montreal, 10-12 December, 2013. Disponível em: <http://www.icao.int/meetings/ mpl/Documents/Forms/Allitems.aspx>. Acesso em: 11 fev. 2015.

INTERNATIONAL CIVIL AVIATION ORGANIZATION - ICAO. Multi-Crew Pilot Licence (MPL). July, 2013. Disponível em: <http://www.icao.int/icao/en/trivia/peltrgFAQ.htm>. Acesso em: 4 fev. 2015.

INTERNATIONAL CIVIL AVIATION ORGANIZATION - ICAO. Manual on Aeroplane Upset Prevention and Recovery Training. Doc 10011. AN/506. First Edition, 2014.

PEREZ GONZALEZ, J. D. Automation in aviation. 2011. Disponível em: <http://aviationknowledge. wikidot.com/aviation:automation>. Acesso em: 9 jul. 2015.

PERRENOUD, P. Construir competências desde a escola. Porto Alegre: Artmed, 1999.

RAMOS, M. N. Qualificação, competências e certificação: visão educacional. Formação, Brasília, v. 1, n. 2, p. 19-28, maio 2001a. Disponível em: <http://bvsms.saude.gov.br/bvs/publicacoes/ profae/Revista2002.pdf\#page=19>. Acesso em: 24 out. 2015.

RAMOS, M. N. A pedagogia das competências: autonomia ou adaptação? São Paulo: Cortez, 2001b.

RAMOS, M. N. A educação profissional pela pedagogia das competências e a superfície dos documentos oficiais. Educação e Sociedade, Campinas, v. 23, n. 80, p. 401-422, set. 2002.

RIBEIRO, E. F. A formação do piloto de linha aérea: caso Varig. O ensino aeronáutico acompanhando a evolução tecnológica. 2008. 386f. Tese (Doutorado em História) - Pontifícia Universidade Católica do Rio Grande do Sul, Porto Alegre, 2008. 
RONDON, M. H. D. de F. A formação e o exercício profissional de piloto da aviação civil: uma política em questão. 2012. 206f. Dissertação (Mestrado em Educação) - Universidade Católica de Brasília, Brasília, 2012.

RONDON, M. H. D. de F.; CAPANEMA, C. F.; FONTES, R. S. de. A interação homem-máquina nas aeronaves tecnologicamente avançadas. Aviation in Focus, v. 5, n. 2, p. 50-60, jul./dez. 2014.

SCHROEDER, C.; HARMS, D. MPL represents a state-of-the-art ab initio airline pilot training programme. The ICAO Journal, v. 62, n. 3, p. 15-16, 31-32, 2007. Disponível em: <http://www. casa.gov.au/wcmswr/_assets/main/fcl/multicrew/icaoarticle.pdf>. Acesso em: 13 fev. 2015.

UNITED STATES. Federal Aviation Administration. General aviation technically advanced aircraft, FAA-Industry, safety study: final report of TAA safety study team. August 22, 2003. Disponível em: <http://www.faa.gov/training_testing/training/fits/research/media/TAA\%20Final\%20Report.pdf>. Acesso em: 8 jan. 2015.

WIKANDER, R.; DAHLSTRÖM, N. The Multi Crew Pilot License. Revolution, evolution or not even a solution? A Review and analysis of the emergence, current situation and future of the MultiCrew Pilot License (MPL). 2014. 151 f. Bachelor thesis (School Aviation) - Lund University, Lund, Sweden, 2014.

\section{REJANE DE SOUZA FONTES}

Doutora em Educação pela Universidade Estadual do Rio de Janeiro - UERJ -, Rio de Janeiro, Rio de Janeiro, Brasil; pós-doutoranda do Programa de Pós-Graduação em História - PUC-RS -, Porto Alegre, Rio Grande do Sul, Brasil; especialista em Regulação da Agência Nacional de Aviação Civil - Anac -, Rio de Janeiro, Rio de Janeiro, Brasil

rejane.fontes@anac.gov.br

CLAUDIA MUSA FAY

Professora Doutora do Programa de Pós-Graduação em História e da Faculdade de Ciências Aeronáuticas da Pontifícia Universidade Católica do Rio Grande do Sul - PUC-RS -, Porto Alegre, Rio Grande do Sul, Brasil cmusafay@pucrs.br 